\title{
The Associations of Tonsillectomy with Adenoidectomy with Pneumonia and Appendicitis Based on National Sample Cohort Data from the Korean National Health Insurance Service
}

\author{
Junhui Jeong ${ }^{1 \odot}$ Jung Kyu Choi ${ }^{2}$ Hyun Seung Choi ${ }^{10}$ Chang Eui Hong ${ }^{1 \odot}$ Hyang Ae Shin ${ }^{10}$ \\ Jung Hyun Chang ${ }^{10}$ \\ ${ }^{1}$ Department of Otorhinolaryngology, National Health Insurance \\ Service Ilsan Hospital, Goyang, Korea \\ 2 Department of Policy Research Affairs, National Health Insurance \\ Service Ilsan Hospital, Goyang, Korea \\ Address for correspondence Jung Hyun Chang, MD, PhD, \\ Department of Otorhinolaryngology, National Health Insurance \\ Service Ilsan Hospital, 100 Ilsan-ro, Ilsandong-gu, Goyang 10444, \\ Korea (e-mail: jhrhino.chang@gmail.com).
}

Int Arch Otorhinolaryngol 2021;25(4):e545-e550.

\begin{abstract}
Keywords

- tonsillectomy

- adenoidectomy

- pneumonia

- appendectomy

- appendicitis

Introduction The association between tonsillectomy with adenoidectomy (T\&A) with appendicitis is controversial, and the association of T\&A with pneumonia has not been investigated.

Objective To investigate the associations of T\&A with pneumonia and appendicitis using data from the Korean National Health Insurance Service National Sample Cohort. Methods We selected patients between the ages of 3 and 10 years who had undergone T\&A in 2005 and were monitored since the performance of the T\&A until 2013. The control group was established to have similar propensities for demographic characteristics compared to the T\&A group. For eight years after the T\&A, the number of patients with a diagnosis of pneumonia, patients who were admitted due to pneumonia, and those who underwent appendectomy were analyzed. The risk factors for pneumonia and appendectomy were analyzed.

Results The number of pneumonia diagnoses was significantly higher in the T\&A group than in the control group $(p=0.023)$, but there were no significant differences in the number of admissions due to pneumonia between the 2 groups $(p=0.155)$. Younger age and T\&A were significant risk factors for the development of pneumonia. There were no significant differences in the number of appendectomies between the T\&A and the control groups ( $p=0.425$ ), neither were there significant risk factors for appendectomy.

Conclusion Tonsillectomy with adenoidectomy was associated with an increase in pneumonia diagnoses, but it was not associated with the number of appendectomies. The associations of T\&A with pneumonia and appendicitis were analyzed in this population-based study.
\end{abstract}

received

May 3, 2020

accepted

October 12, 2020

published online

February 19, 2021
DOI https://doi.org/ 10.1055/s-0040-1722159. ISSN 1809-9777.

\footnotetext{
(C) 2021. Fundação Otorrinolaringologia. All rights reserved.

This is an open access article published by Thieme under the terms of the Creative Commons Attribution-NonDerivative-NonCommercial-License, permitting copying and reproduction so long as the original work is given appropriate credit. Contents may not be used for commercial purposes, or adapted, remixed, transformed or built upon. (https://creativecommons.org/ licenses/by-nc-nd/4.0/)

Thieme Revinter Publicações Ltda., Rua do Matoso 170, Rio de Janeiro, RJ, CEP 20270-135, Brazil
} 


\section{Introduction}

Tonsillectomy with adenoidectomy (T\&A) is a common surgery for children, and it is indicated for frequent tonsillitis and obstructive sleep apnea. ${ }^{1}$ The tonsil and appendix are components of mucosa-associated lymphoid tissue (MALT). The removal of the tonsils was associated with alterations in the MALT. ${ }^{2-5}$ The function of the appendix may be increased instead of that of the tonsils after tonsillectomy. The change in the MALT may influence not only gastrointestinal diseases but also pulmonary diseases such as pneumonia, because the tonsils have an immunologic role against airborne antigens entering the nose and mouth.

To date, several studies have been performed to reveal the association between tonsillectomy with or without adenoidectomy and appendicitis. ${ }^{3-6}$ However, whether T\&A is related to appendicitis or appendectomy is controversial. Meanwhile, the association of T\&A with pneumonia has not been investigated until now.

In the present study, we analyzed the associations of T\&A with subsequent pneumonia and appendicitis using data from the Korean National Health Insurance Service National Sample Cohort.

\section{Materials and Methods}

\section{Patients}

The present study included data from the National Health Insurance Service National Sample Cohort in Korea, which represents a subsample of $2 \%$ of the entire National Health Insurance Service database from 2002 to 2013. From the national sample cohort data, we selected patients between the ages of 3 and 10 years who had urdergone T\&A in 2005 and who were monitored since the performance of T\&A until 2013. We excluded patients who underwent T\&A in any year other than 2005, and those who had pneumonia (in the analysis of the association with pneumonia) or were submitted to appendectomy (in the analysis of the association with appendicitis) between 2002 and 2005. The T\&A group was established for the analysis of the association with pneumonia and appendicitis respectively.

All people in Korea are obligated to join the National Health Insurance Service. Accordingly, the approximately 1 million total subjects in the national sample cohort each year represent about $2 \%$ of the total Korean population (of 50 million people). Therefore, the results in the present study are a fair representation of the entire Korean population. The control group was established for the analysis of the association with pneumonia and appendicitis respectively; it was 5 times larger than the T\&A group, and comprised people who did not undergo T\&A between 2002 to 2013 and those who did not have pneumonia (in the analysis of the association with pneumonia) or were not submitted to appendectomy (in the analysis of the association with appendicitis) between 2002 and 2005. These individuals were selected to match the T\&A group with regard to sex, age, level of income, residence, and type of
National Health Insurance. Thus, the two matched groups had similar propensities for these demographic characteristics. Individual characteristics that could influence the incidence of pneumonia (such as, past medical and surgical history, family history, allergies, presence of comorbidities, prematurity, malnutrition, air pollution, breastfeeding, and vaccination for pneumococcus) were not considered, but may be negligible in the design of the present study due to the propensity-matched control group and large sample size.

The present study was performed in accordance with the 1964 Declaration of Helsinki and its later amendments or comparable ethical standards. The Institutional Review Board approved the study (NHIMC 2019-04-034), and exempted it from taking the written informed consent of the patients.

\section{Data Analysis}

From 2005 to 2013, the numbers of patients with a diagnosis of pneumonia, patients who were admitted due to pneumonia, and those who underwent appendectomy were analyzed. The analysis used the main diagnostic codes from the International Classification of Diseases that were recorded during the visits to the clinic and admissions of each patient. The patients were divided into 4 groups according to age at the time of the performance of T\&A as follows: 3 to 4 years old; 5 to 6 years old; 7 to 8 years old; and 9 to 10 years old. Additionally, the risk factors for pneumonia and appendectomy were analyzed.

\section{Definition of the Disease}

The main diagnostic codes associated with pneumonia in the International Classification of Diseases were J10.0 (influenza with pneumonia, seasonal influenza virus identified); J11.0 (influenza with pneumonia, virus not identified); J12 (viral pneumonia, not elsewhere classified); J13 (pneumonia due to Streptococcus pneumoniae); J14 (pneumonia due to Haemophilus influenzae); J15 (bacterial pneumonia, not elsewhere classified); J16 (pneumonia due to other infectious organisms, not elsewhere classified); J17 (pneumonia in diseases classified elsewhere); and J18 (pneumonia, organism unspecified). Community-acquired and hospital-acquired pneumonia could not be classified in the present study because there were no separate codes in the classification of diseases. The claim codes for appendectomy in the Korean National Health Insurance Service were Q2861, Q2862, and Q2863.

\section{Statistical Analysis}

Differences in the diagnosis of pneumonia and admission due to pneumonia and differences in the performance of appendectomy were compared between the T\&A group and control group using Chi-squared test. The risk factors for pneumonia and appendectomy were analyzed using a Cox proportional hazards model with univariate and multivariate analyses to evaluate the hazard ratio (HR). The statistical analysis was performed using the SAS 9.3 (SAS Institute, Cary, NC, US) software. 


\section{Results}

Differences in the Diagnosis of Pneumonia between the T\&A and Control Groups

The total number of patients was 175 in the T\&A group, and 875 in the control group. The number of diagnoses of pneumonia was significantly higher in the T\&A group than in the control group ( $p=0.023)$, but there were no significant differences in the number of admissions due to pneumonia between the 2 groups ( $p=0.155$ ) (-Table 1 ).

\section{Risk Factors for Pneumonia in the Cox Proportional Hazards Model with Univariate and Multivariate Analysis}

The HRs of several factors such as sociodemographic components and T\&A for pneumonia were analyzed. Younger age $(\mathrm{HR}=0.79,95 \%$ confidential interval $[95 \% \mathrm{CI}]=0.728$ to 0.864 in the univariate analysis; and $\mathrm{HR}=0.80,95 \%$ $\mathrm{CI}=0.727$ to 0.873 in the multivariate analysis) and $\mathrm{T} \& \mathrm{~A}$ $(\mathrm{HR}=1.52,95 \% \mathrm{CI}=1.062$ to 2.167 in the univariate analysis; and $\mathrm{HR}=1.53,95 \% \mathrm{CI}=1.072$ to 2.189 in the multivariate analysis) were significant risk factors for the development of pneumonia in the Cox proportional hazards model on the univariate and multivariate analyses (-Table 2 ).

\section{Differences in the Incidence of Appendectomy between the T\&A and Control Groups}

The total number of patients was 265 in the T\&A group and 1,325 in the control group. There were no significant differences in the number of appendectomies between the groups $(p=0.425)$ (-Table 3$)$.

\section{Risk Factors for Appendectomy in the Cox Proportional Hazards Model with Univariate and Multivariate Analysis}

The HRs of several factors such as sociodemographic components and T\&A for appendectomy were analyzed. There were no significant risk factors for the performance of appendectomy in the Cox proportional hazards model on the univariate and multivariate analyses ( - Table 4 ).

\section{Discussion}

The tonsils and adenoids are secondary lymphoid tissues that present an immune response against airborne antigens. These consist of B-cell lymphocytes (50\% to 65\%), T-cell lymphocytes (40\%), and mature plasma cells $(3 \%){ }^{1}$ The tonsils and adenoids play a role not only as components of the MALT, but also in a mucosal type of adaptive immunity. 7,8

Table 1 Differences in the number of diagnoses of pneumonia and admissions due to pneumonia between the tonsillectomy with adenoidectomy and control groups

\begin{tabular}{|c|c|c|c|c|c|}
\hline \multirow{2}{*}{\multicolumn{2}{|c|}{\begin{tabular}{|l} 
\\
Total
\end{tabular}}} & \multirow{2}{*}{$\begin{array}{l}\begin{array}{l}\text { Control } \\
\text { group (\%) }\end{array} \\
875(83.3) \\
\end{array}$} & \multirow{2}{*}{$\begin{array}{l}\text { T\&A } \\
\text { group (\%) } \\
175(16.7)\end{array}$} & \multirow{2}{*}{$\begin{array}{l}\text { Total (\%) } \\
1,050(100.0)\end{array}$} & \multirow[t]{2}{*}{$p$-value } \\
\hline & & & & & \\
\hline \multirow[t]{2}{*}{ Sex } & Male & $540(61.7)$ & $108(61.7)$ & $648(61.7)$ & \multirow[t]{2}{*}{1} \\
\hline & Female & $335(38.3)$ & $67(38.3)$ & $402(38.3)$ & \\
\hline \multirow{4}{*}{$\begin{array}{l}\text { Age at the } \\
\text { performance of } \\
\text { T\&A }\end{array}$} & $3-4$ years old & $60(6.9)$ & $12(6.9)$ & $72(6.9)$ & \multirow[t]{4}{*}{1} \\
\hline & $5-6$ years old & $290(33.1)$ & $58(33.1)$ & $348(33.1)$ & \\
\hline & $7-8$ years old & 305 (34.9) & 61 (34.9) & 366 (34.9) & \\
\hline & $9-10$ years old & $220(25.1)$ & $44(25.1)$ & $264(25.1)$ & \\
\hline \multirow[t]{5}{*}{ Level of income } & 1st quintile & $60(6.9)$ & $12(6.9)$ & $72(6.9)$ & \multirow[t]{5}{*}{1} \\
\hline & 2nd quintile & $110(12.6)$ & $22(12.6)$ & $132(12.6)$ & \\
\hline & 3rd quintile & $200(22.9)$ & $40(22.9)$ & $240(22.9)$ & \\
\hline & 4th quintile & $280(32.0)$ & $56(32.0)$ & $336(32.0)$ & \\
\hline & 5th quintile & $225(25.7)$ & $45(25.7)$ & $270(25.7)$ & \\
\hline \multirow{2}{*}{$\begin{array}{l}\text { Type of } \\
\text { National Health } \\
\text { Insurance }\end{array}$} & Employee & $510(58.3)$ & $102(58.3)$ & $612(58.3)$ & \multirow[t]{2}{*}{1} \\
\hline & Regional & $365(41.7)$ & $73(41.7)$ & $438(41.7)$ & \\
\hline \multirow[t]{4}{*}{ Residence } & Seoul (capital) & $145(16.6)$ & $29(16.6)$ & $174(16.6)$ & \multirow[t]{4}{*}{1} \\
\hline & Metropolitan & $245(28.0)$ & $49(28.0)$ & $294(28.0)$ & \\
\hline & $\begin{array}{l}\text { City (small- and } \\
\text { medium-sized) }\end{array}$ & 445 (50.9) & 89 (50.9) & $534(50.9)$ & \\
\hline & County & $40(4.6)$ & $8(4.6)$ & $48(4.6)$ & \\
\hline \multicolumn{2}{|c|}{ Diagnosis of pneumonia } & $134(15.3)$ & $39(22.3)$ & $173(16.5)$ & $0.023^{*}$ \\
\hline \multicolumn{2}{|c|}{ Admission due to pneumonia } & $19(2.2)$ & $7(4.0)$ & $26(2.5)$ & 0.155 \\
\hline
\end{tabular}

Abbreviation: T\&A, tonsillectomy with adenoidectomy.

Note: ${ }^{*}$-value $<0.05$. 
Table 2 Hazard ratios for pneumonia in the Cox proportional hazards model with univariate and multivariate analysis

\begin{tabular}{|c|c|c|c|c|c|}
\hline & & \multicolumn{2}{|c|}{ Univariate analysis } & \multicolumn{2}{|c|}{ Multivariate analysis } \\
\hline & & HR & $95 \% \mathrm{Cl}$ & $\mathrm{HR}$ & $95 \% \mathrm{Cl}$ \\
\hline \multirow[t]{2}{*}{ Sex } & Male & 1 & & 1 & \\
\hline & Female & 1.11 & $0.816-1.498$ & 1.12 & $0.819-1.540$ \\
\hline Age & Year & $0.79^{*}$ & $0.728-0.864$ & $0.80^{*}$ & $0.727-0.873$ \\
\hline \multirow[t]{5}{*}{ Level of income } & 1st quintile & 1 & & 1 & \\
\hline & 2nd quintile & 1.17 & $0.605-2.255$ & 0.99 & $0.500-1.951$ \\
\hline & 3rd quintile & 0.94 & $0.501-1.746$ & 0.91 & $0.474-1.745$ \\
\hline & 4th quintile & 0.79 & $0.427-1.451$ & 0.81 & $0.432-1.531$ \\
\hline & 5th quintile & 0.84 & $0.453-1.572$ & 0.96 & $0.509-1.819$ \\
\hline \multirow[t]{2}{*}{ Type of National Health Insurance } & Employee & 1 & & 1 & \\
\hline & Regional & 0.82 & $0.602-1.114$ & 0.90 & $0.652-1.245$ \\
\hline \multirow[t]{4}{*}{ Residence } & Seoul (capital) & 1 & & 1 & \\
\hline & Metropolitan & 1.05 & $0.667-1.638$ & 1.14 & $0.718-1.793$ \\
\hline & City (small- and medium- sized) & 0.91 & $0.599-1.379$ & 0.94 & $0.613-1.432$ \\
\hline & County & 0.84 & $0.368-1.908$ & 1.03 & $0.427-2.480$ \\
\hline \multirow[t]{2}{*}{$T \& A$} & Not performed & 1 & & 1 & \\
\hline & Performed & $1.52^{*}$ & $1.062-2.167$ & $1.53^{*}$ & $1.072-2.189$ \\
\hline
\end{tabular}

Abbreviations: 95\%Cl, 95\% confidential interval; HR, hazard ratio; T\&A, tonsillectomy with adenoidectomy.

Note: ${ }^{*} p$-value $<0.05$.

Table 3 Differences in the incidence of appendectomy between the tonsillectomy with adenoidectomy and control groups

\begin{tabular}{|c|c|c|c|c|c|}
\hline & & $\begin{array}{l}\text { Control } \\
\text { group (\%) }\end{array}$ & $\begin{array}{l}\text { T\&A } \\
\text { group (\%) }\end{array}$ & Total (\%) & $p$-value \\
\hline Total & & $1,325(83.3)$ & $265(16.7)$ & $1,590(100.0)$ & \\
\hline \multirow[t]{2}{*}{ Sex } & Male & $855(64.5)$ & $171(64.5)$ & $1,026(64.5)$ & \multirow[t]{2}{*}{1} \\
\hline & Female & $470(35.5)$ & $94(35.5)$ & $564(35.5)$ & \\
\hline \multirow{4}{*}{$\begin{array}{l}\text { Age at the } \\
\text { performance of } \\
\text { T\&A }\end{array}$} & $3-4$ years old & $135(10.2)$ & $27(10.2)$ & $162(10.2)$ & \multirow[t]{4}{*}{1} \\
\hline & 5-6 years old & $530(40.0)$ & $106(40.0)$ & $636(40.0)$ & \\
\hline & $7-8$ years old & $400(30.2)$ & $80(30.2)$ & $480(30.2)$ & \\
\hline & $9-10$ years old & $260(19.6)$ & $52(19.6)$ & $312(19.6)$ & \\
\hline \multirow[t]{5}{*}{ Level of income } & 1st quintile & $75(5.7)$ & $15(5.7)$ & $90(5.7)$ & \multirow[t]{5}{*}{1} \\
\hline & 2nd quintile & $155(11.7)$ & $31(11.7)$ & $186(11.7)$ & \\
\hline & 3rd quintile & $315(23.8)$ & $63(23.8)$ & $378(23.8)$ & \\
\hline & 4th quintile & $435(32.8)$ & $87(32.8)$ & $522(32.8)$ & \\
\hline & 5th quintile & $345(26.0)$ & $69(26.0)$ & $414(26.0)$ & \\
\hline \multirow{2}{*}{$\begin{array}{l}\text { Type of National } \\
\text { Health Insurance }\end{array}$} & Employee & $795(60.0)$ & $159(60.0)$ & $954(60.0)$ & \multirow[t]{2}{*}{1} \\
\hline & Regional & $530(40.0)$ & $106(40.0)$ & $636(40.0)$ & \\
\hline \multirow[t]{4}{*}{ Residence } & Seoul (capital) & $245(18.5)$ & $49(18.5)$ & $294(18.5)$ & \multirow[t]{4}{*}{1} \\
\hline & Metropolitan & $345(26.0)$ & $69(26.0)$ & $414(26.0)$ & \\
\hline & City (small- and medium-sized) & $680(51.3)$ & $136(51.3)$ & $816(51.3)$ & \\
\hline & County & $55(4.2)$ & $11(4.2)$ & $66(4.2)$ & \\
\hline Appendectomy & Performed & 25 (1.9) & $7(2.6)$ & $32(2.0)$ & 0.425 \\
\hline
\end{tabular}

Abbreviation: T\&A, tonsillectomy with adenoidectomy. 
Table 4 Hazard ratios for appendectomy in the Cox proportional hazards model with univariate and multivariate analysis

\begin{tabular}{|c|c|c|c|c|c|}
\hline & & \multicolumn{2}{|c|}{ Univariate analysis } & \multicolumn{2}{|c|}{ Multivariate analysis } \\
\hline & & HR & $95 \% \mathrm{Cl}$ & HR & $95 \% \mathrm{Cl}$ \\
\hline \multirow[t]{2}{*}{ Sex } & Male & 1 & & 1 & \\
\hline & Female & 0.51 & $0.219-1.170$ & 0.50 & $0.209-1.178$ \\
\hline Age & Year & 1.14 & $0.945-1.373$ & 1.17 & $0.953-1.427$ \\
\hline \multirow[t]{5}{*}{ Level of income } & 1st quintile & 1 & & 1 & \\
\hline & 2nd quintile & 0.96 & $0.240-3.836$ & 1.13 & $0.271-4.687$ \\
\hline & 3rd quintile & 0.70 & $0.191-2.601$ & 0.75 & $0.193-2.880$ \\
\hline & 4th quintile & 0.23 & $0.050-1.004$ & 0.23 & $0.051-1.050$ \\
\hline & 5th quintile & 0.72 & $0.197-2.606$ & 0.64 & $0.170-2.388$ \\
\hline \multirow[t]{2}{*}{ Type of National Health Insurance } & Employee & 1 & & 1 & \\
\hline & Regional & 1.17 & $0.582-2.354$ & 0.94 & $0.447-1.989$ \\
\hline \multirow[t]{4}{*}{ Residence } & Seoul (capital) & 1 & & 1 & \\
\hline & Metropolitan & 2.14 & $0.579-7.906$ & 2.37 & $0.637-8.801$ \\
\hline & City (small- and medium-sized) & 2.17 & $0.639-7.360$ & 2.29 & $0.671-7.800$ \\
\hline & County & 3.02 & $0.505-18.099$ & 2.64 & $0.409-17.078$ \\
\hline \multirow[t]{2}{*}{$T \& A$} & Not performed & 1 & & 1 & \\
\hline & Performed & 1.43 & $0.618-3.302$ & 1.43 & $0.619-3.311$ \\
\hline
\end{tabular}

Abbreviations: 95\% CI, 95\% confidential interval; HR, hazard ratio; T\&A, tonsillectomy with adenoidectomy.

The tonsils are most immunologically active between the ages of 3 and 10 years. ${ }^{1,9}$ There are incompatible studies about the effects of T\&A on immunity. ${ }^{1}$ Ogra $^{2}$ reported a three- to four-fold decrease in the level of immunoglobulin $A$ ( $\operatorname{Ig} A)$ antibody in children previously immunized with live polio vaccine after T\&A. ${ }^{2-4,7,8}$ Other studies reported no salivary IgA reduction or even elevated salivary immunoglobulin levels after tonsillectomy. ${ }^{7,10,11}$ It is still uncertain if the immunologic change after T\&A has an effect on inflammatory diseases such as pneumonia and appendicitis.

Most studies have reported the association of pneumonia with T\&A from the perspective of postoperative respiratory complications. $^{12,13}$ Respiratory complications such as pneumonia after T\&A were reported to be associated with age below 3 years, prematurity, and obstructive sleep apnea. ${ }^{13,14}$

Meanwhile, a lack of exclusive breastfeeding, exposure to cigarette smoke and air pollution, malnutrition, and conditions of poverty were reported to be risk factors for the development of child pneumonia, ${ }^{15}$ and the severity of the pneumonia was reported to be associated with hypoxemia, altered mental status, ages lower than 3 to 6 months, dyspnea, multilobar infiltrates, and moderate/large pleural effusions after a systematic review. ${ }^{16}$ It was reported that the incidence of pneumonia decreased with age. ${ }^{17}$ In one study that evaluated the long-term risk of respiratory diseases including pneumonia following T\&A in childhood, tonsillectomy with or without adenoidectomy was not associated with a significant relative risk of pneumonia. ${ }^{18}$

In the present study, T\&A was associated with an increase in pneumonia. However, increasing age was also linked with a lower rate of pneumonia in the present study, and this finding could be attributed to the effect of age on a decreased rate of post-T\&A complications and the decreased incidence of pneumonia. Respiratory allergies such as allergic rhinitis and possibly consequent mouth breathing could affect a higher rate of pneumonia in the T\&A group even after T\&A. If the patient presents risk factors for pneumonia, T\&A should be decided carefully.

Because there has been no evidence as to whether the change in immunity after T\&A could increase the possibility of pneumonia, which factor contributed to the pneumonia more than the others is unclear. In further researches, the association of T\&A with lower respiratory infections such as pneumonia should receive the attention of clinicians.

To date, there have been several reports about the association of acute appendicitis or appendectomy with tonsillectomy or $\mathrm{T} \& \mathrm{~A}$, and the outcomes have been controversial. Andreu-Ballester et al. $^{3,4}$ reported an association between tonsillectomy and subsequent acute appendicitis. Kim et al. ${ }^{5}$ reported that the risk of appendectomy was higher in the tonsillectomy group only among women. On the contrary, a different report on the lack of association between tonsillectomy and subsequent appendectomy has also been published. ${ }^{6}$ The association of tonsillectomy and other inflammatory bowel diseases such as Crohn disease and ulcerative colitis has also been noted. One meta-analysis ${ }^{19}$ found that tonsillectomy was associated with an increased risk of developing Crohn disease, but not ulcerative colitis.

Andreu Ballester et al. ${ }^{4}$ reported that tonsillectomy would induce deficiency in the MALT, and that lymphoid tissue in the appendix would subsequently make up for the deficiency; thus, the appendix would be more likely to be inflamed or 
infected in individuals who have previously undergone tonsillectomy. ${ }^{4}$ However, Stringer and Horwood ${ }^{6}$ noted that there was a big difference between an enrolled patient's age (average: 45.62 years) and surgery age (tonsillectomy: 9.92 years, adenoidectomy: 8.64 years, appendectomy: 22.01 years) in cross-sectional study by Andreu Ballester et al., ${ }^{4}$ and that there could also be a recall bias. They presented longitudinal prospective data that indicated that the rate of appendectomy was slightly higher in patients who had a history of tonsillectomy, but this finding was not significant. ${ }^{6}$

The rate of appendectomy was slightly higher in the T\&A group than in the control group in the present study, but not to a significant degree. There have been few studies to date that have considered the association between tonsillectomy with or without adenoidectomy and appendicitis. Regarding changes in the MALT and secretory IgA after T\&A, further studies are necessary to evaluate the effects of T\&A on gastrointestinal inflammatory disease.

In the analysis of the associations between T\&A and pneumonia and appendicitis, whether T\&A could induce decreased immunity and increase infection and inflammation accordingly is important to consider. However, because to date there has been a lack of clinical and experimental reports on the associations between T\&A and pneumonia and appendicitis, we could not come to a clear interpretation regarding this population-based, large dataset. More studies are necessary to reveal the effects of T\&A on immunity.

The present study has several limitations. Firstly, it is a retrospective study, and due to the limits of our methodology, the analyses were performed with diagnostic codes, so the real incidence of the diseases could be different. Secondly, patients who were submitted to adenoidectomy only or tonsillectomy only were not included in the study because they represented only a small number of patients. In further studies with more specific surgery classifications, including tonsillectomy only, adenoidectomy only, and T\&A, more meaningful results will be obtained, and they should be helpful in deciding whether T\&A is associated with pneumonia and appendicitis. Nevertheless, the present study has relevance because the associations between T\&A and pneumonia and appendicitis were observed in a large-scale, population-based, big-data study.

\section{Conclusion}

An increase in cases of pneumonia was associated with T\&A, but it did not appear to promote an increase in the number of appendectomies. The relationships between immunologic changes after T\&A and pneumonia and appendicitis should be further evaluated.

\section{Funding}

The present study was funded by a grant from the National Health Insurance Service Ilsan Hospital (NHIMC 2016-20016). The study used National Health Insurance ServiceNational Sample Cohort (NHIS-NSC) data (NHIS-2017-2316) compiled by the National Health Insurance Service in Korea.

\section{Conflict of Interests}

The authors have no conflict of interests to declare.

\section{References}

1 Ramos SD, Mukerji S, Pine HS. Tonsillectomy and adenoidectomy. Pediatr Clin North Am 2013;60(04):793-807

2 Ogra PL. Effect of tonsillectomy and adenoidectomy on nasopharyngeal antibody response to poliovirus. N Engl J Med 1971;284 (02):59-64

3 Andreu-Ballester JC, Colomer RE, Millán Scheiding M, Ballester F. Tonsillectomy and risk of acute appendicitis. Am J Gastroenterol 2003;98(12):2806-2807

4 Andreu Ballester JC, Ballester F, Colomer Rubio E, Millán Scheiding M. Association between tonsillectomy, adenoidectomy, and appendicitis. Rev Esp Enferm Dig 2005;97(03):179-186

5 Kim SY, Min C, Oh DJ, Choi HG. Increased risk of appendectomy due to appendicitis after tonsillectomy in women: A longitudinal follow-up study using a national sample cohort. Medicine (Baltimore) 2019;98(19):e15579

6 Stringer MD, Horwood LJ. Lack of association between tonsillectomy and subsequent appendicectomy. J Pediatr Surg 2008;43 (03):586-587

7 Brandtzaeg P. Immunology of tonsils and adenoids: everything the ENT surgeon needs to know. Int J Pediatr Otorhinolaryngol 2003;67(Suppl 1):S69-S76

8 Brandtzaeg P. Immune functions of nasopharyngeal lymphoid tissue. Adv Otorhinolaryngol 2011;72:20-24

9 Mitchell RB, Archer SM, Ishman SL, et al. Clinical Practice Guideline: Tonsillectomy in Children (Update). Otolaryngol Head Neck Surg 2019;160(1_suppl):S1-S42

10 D’Amelio R, Palmisano L, Le Moli S, Seminara R, Aiuti F. Serum and salivary IgA levels in normal subjects: comparison between tonsillectomized and non-tonsillectomized subjects. Int Arch Allergy Appl Immunol 1982;68(03):256-259

11 Lenander-Lumikari M, Tenovuo J, Puhakka HJ, et al. Salivary antimicrobial proteins and mutans streptococci in tonsillectomized children. Pediatr Dent 1992;14(02):86-91

12 Allareddy V, Martinez-Schlurmann N, Rampa S, et al. Predictors of Complications of Tonsillectomy With or Without Adenoidectomy in Hospitalized Children and Adolescents in the United States, 20012010: A Population-Based Study. Clin Pediatr (Phila) 2016;55(07): 593-602

13 Kou YF, Sakai M, Shah GB, Mitchell RB, Johnson RF. Postoperative respiratory complications and racial disparities following inpatient pediatric tonsillectomy: A cross-sectional study. Laryngoscope 2019;129(04):995-1000

14 Martins RO, Castello-Branco N, Barros JL, Weber SA. Risk factors for respiratory complications after adenotonsillectomy in children with obstructive sleep apnea. J Bras Pneumol 2015;41(03): 238-245

15 Nguyen TK, Tran TH, Roberts CL, Graham SM, Marais BJ. Child pneumonia - focus on the Western Pacific Region. Paediatr Respir Rev 2017;21:102-110

16 Dean P, Florin TA. Factors Associated With Pneumonia Severity in Children: A Systematic Review. J Pediatric Infect Dis Soc 2018;7 (04):323-334

17 Jain S, Williams DJ, Arnold SR, et al;CDC EPIC Study Team. Community-acquired pneumonia requiring hospitalization among U.S. children. N Engl J Med 2015;372(09):835-845

18 Byars SG, Stearns SC, Boomsma JJ. Association of Long-Term Risk of Respiratory, Allergic, and Infectious Diseases With Removal of Adenoids and Tonsils in Childhood. JAMA Otolaryngol Head Neck Surg 2018;144(07):594-603

19 Sun W, Han X, Wu S, Yang C. Tonsillectomy and the risk of inflammatory bowel disease: A systematic review and metaanalysis. J Gastroenterol Hepatol 2016;31(06):1085-1094 